\title{
SYNTHESIS, CHARACTERIZATION AND ANTIMICROBIAL ANALYSIS OF PHENAZINEAZO-1-NAPHTHOL PRODUCED FROM PHENAZINE-1- CARBOXYLIC ACID ISOLATED FROM PSEUDOMONAS AERUGINOSA
}

\author{
Onunkwo, I. C., \\ Nigeria Maritime University \\ (NMU), Okerenkoko, Delta \\ State, Nigeria
}

\author{
Okerulu, I. O., \\ Nnamdi Azikiwe University \\ (NAU), Awka, Anambra \\ State, Nigeria
}

\author{
Okonkwo, O. J. \\ Tshwane University of \\ Technology, Arcadia, \\ Pretoria, South Africa
}

AbstracT - The search for effective antibiotics continues among scientists as more resistant pathogenic microorganisms evolve, and some already existing antibiotics used in treatment of infections are gradually becoming less effective against the pathogens causing the infections thus, making life unbearable to their hosts. Phenazines are para diazine with annular two nitrogen atoms at 1,4 positions joined to two phenyl group in a side by side pattern. The derivatives of the compound are primarily produced from microorganisms and can also be synthesized, example of this is phenazine-1-carboxylic acid (PCA). In the present study, phenazine-1-carboxylic acid was biosynthesized from Pseudomonas aeruginosa isolated from soil. Subsequently, phenazineazo-1naphthol was synthesized from the produced phenazine-1-carboxylic acid following amidation with Ammonium carbonate and Hoffmann degradation reactions to reduce the compound to phenazineamine under reflux condition of $50{ }^{\circ} \mathrm{C}$ before diazotization and coupling with 1-naphthol. The results obtained from the UV-vis, IR and NMR spectra were able to elucidate the important peaks in the compound at reasonable extents. The concentrations of $50 \mu \mathrm{g} / \mathrm{mL}, 100 \mu \mathrm{g} / \mathrm{mL}, 150$ $\mu \mathrm{g} / \mathrm{mL}, 200 \mu \mathrm{g} / \mathrm{mL}, 30 \mu \mathrm{g} / \mathrm{mL}$ Augmentin (Au, control drug), $30 \mu \mathrm{g} / \mathrm{mL}$ Oflocitoxin (OFX, control drug) and raw sample of the compound were able to inhibit Staphylococcus aureus and Escherichia coli at some millimeter ranges while Aspergillus fumigatus was inhibited by all the sample concentrations but resisted $30 \mu \mathrm{g} / \mathrm{mL}$ Augmentin (Au) and Oflocitoxin (OFX) control drugs from the antimicrobial analysis carried out. In general, the compound was active against the organisms when compared to the concentrations of control antibiotic drugs used. The minimum inhibitory concentration of the compound was estimated at 50 $\mu \mathrm{g} / \mathrm{mL}$ concentrations.

Keywords: Phenazineamine, 1-naphthol, Phenazine, Phenazineazo-1-naphthol, Antimicrobial.

\section{INTRODUCTION}

Natural phenazines are coloured secondary metabolites primarily containing heterocyclic nitrogen isolated from Pseudomonas, Streptomyces, and few other genera from soil or marine habitats [1], and phenazine compound secreted by Pseudomonas aeruginosa are largely found as phenazine-1carboxylic acid $[2,3]$. The toxicity problems caused by some synthetic dyes to the environment have created interest towards natural dyes with proven wide applications, more especially from microbial sources [4]. Coloured organic compound, for example azo dyes are used to impart colours to substrates and can be used for other applications [5]. The synthesis of azo coloured compounds or dyes involves diazotization and azo coupling reactions; diazotization is a strong chemical reaction to produce diazonium salts (electrophile) and azo coupling involves the electrophile attack on the available nucleophile group (electron withdrawing groups - example is hydroxyl group such as phenol) at ice temperatures [6]. Most azo coloured compounds or dyes possess resistance to oxidizing agent, with non-toxicity, non-basicity and slight acidity properties [7]. Azo-naphthol dyes 


\section{International Journal of Engineering Applied Sciences and Technology, 2021 Vol. 6, Issue 4, ISSN No. 2455-2143, Pages 27-33 \\ Published Online August 2021 in IJEAST (http://www.ijeast.com)}

possess interesting colours on substrates (fabrics) and may be used for other purposes [8].

Phenazine-1-carboxylic acid (PCA), the precursor of all other phenazines produced by $P$. aeruginosa, is (a brightly yellow coloured compound) biosynthesized from chorismate by genes constituting the redundant phzA1-G1 and phzA2-G2 operons (phenazine enzyme) of which each encodes a full set of functional phenazine-1-carboxylic acid biosynthetic enzymes [1, 9]. Some naturally occurring phenazines (for example, phenazine-1-carboxylic acid) are commonly referred to "phenazine antibiotics", as a result of their primary function as bacterial warfare agents used in microbial competition [10]. This phenazine natural products possess great antiparasitic or antibiotic activities against some strains of bacteria and fungi alike and also displayed arrays of interesting therapeutic relevant and biological activities thus, has been nicknamed as "Tubermycin B" because of its antibiotic activity against Mycobacterium tuberculosis [2-3, 10-11], and these have given room for more studies and analysis to be carried out on them at different bases. On that note, since azo coloured compounds or dyes have displayed wide applications in today's industries (60-70\% of the market presence) for many purposes such as dyeing of fabrics, food colorants, pharmaceutical [12-14] and antimicrobial agents [15-16, 20], therefore phenazineazo-1-naphthol (synthesized from phenazine-1-carboxylic acid) is proposed to possess antibiotic activity against some strains of microorganisms.

\section{MATERIAL AND METHODS}

The analytical chemical reagent purchased were used without further purification. The equipment used are Petri dishes, incubator, melting point apparatus (microscopic), autoclave (Desco), centrifuge (Health Med. England. 80-2), Meta-lab water bath (MSI 17B), orbital shaker/vibrator (mechanical HY-4), $\mathrm{pH}$ meter (Thermo scientific PHS-3C), magnetic stirrer (constant temp. HY-3D), weighing balance (Electric FA2004), UV-Visible spectrophotometer (Metro UV5800PC), FT-IR spectrometer (Agilent Happ-Genzel), thermocool refrigerator (HTF-259H), NMR spectrometer (Agilent-NMR-vnmrs 400).

\section{Collection and preparation of soil sample $-[16$,} 20]

The soil sample was collected randomly after digging $100 \mathrm{~cm}$ with a washed and sterilized container from the waste disposal channel of A. C Drug Company Limited, Thinkers Corner Enugu, Enugu State (swampy area channeled to a flowing stream). The soil sample was serially diluted following Ten-fold dilution method by addition of the soil sample $(1 \mathrm{~g})$ into a $100 \mathrm{~mL}$ volumetric flask and then made up to the mark with de-ionized water $\left(10^{-1}\right)$. Other dilutions $\left(10^{-2}, 10^{-3}, 10^{-4}\right.$ and $\left.10^{-5}\right)$ were prepared by serially diluting $1 \mathrm{~mL}$ to the remaining four test-tubes containing $9 \mathrm{~mL}$ of de-ionized water.

\section{Isolation of Pseudomonas aeruginosa - $[16,20]$}

Following the manufacturers guide, Cetrimide agar (selective medium for $P$. aeruginosa) was prepared and sterilized in an autoclave at $121^{\circ} \mathrm{C}$ for 15 mins and left to cool on a sterilized and microorganism-free environment to about $40-60{ }^{\circ} \mathrm{C}$. The prepared media $(20 \mathrm{~mL})$ was poured into each of the petri dishes containing $1 \mathrm{~mL}$ of different dilutions of the contaminated soil samples and the whole agar plates was incubated for $24 \mathrm{~h}$ at $37{ }^{\circ} \mathrm{C}$. After $24 \mathrm{~h}$ morphologically the bacterial colony developed on the agar plates. A pure culture of the isolate was prepared by taking streaks from the agar plates on a fresh Cetrimide agar media of the isolate in a bijou bottles, which were incubated at $37^{\circ} \mathrm{C}$ for $24 \mathrm{~h}$ and stocked.

3. Characterization of the P. aeruginosa - [16-17, 20].

Isolates were characterized and identified using conventional microbiological procedures such as colony and culture morphology, gram staining reactions and biochemical tests such as catalase test, oxidase test, indole test, hydrogen sulphide test, motility test and sugar fermentation test as described below.

\section{i. Colony and culture morphology}

The colony and morphology of Pseudomonas aeruginosa was identified by physical observations. A creamy raised colony and smooth edge was observed.

\section{ii. Gram staining}

A drop of sterile normal saline was placed on a clean slide and the isolate was collected using an inoculating loop. The isolate was emulsified on the slide containing the normal saline forming a thin smear. It was left to dry and then heat fixed using a Bunsen burner flame. The slides were placed on a staining rack. Crystal violet was applied on it for 60 secs, drained off and washed with water. Lugol's iodine was applied and allowed to act for $1 \mathrm{~min}$. It was rinsed off with water and acetone alcohol applied until no colour 


\section{International Journal of Engineering Applied Sciences and Technology, 2021 Vol. 6, Issue 4, ISSN No. 2455-2143, Pages 27-33 \\ Published Online August 2021 in IJEAST (http://www.ijeast.com)}

appeared to flow from the preparation for $30 \mathrm{secs}$, before washing with water. There was decolorization of the organism colony when viewed under the microscope, showing a gram negative organism.

\section{iii. Indole test}

Peptone water $(1.5 \mathrm{~g})$ was dissolved in $100 \mathrm{~mL}$ distilled water, autoclaved for 15 mins at $121{ }^{\circ} \mathrm{C}$, then cooled and inoculated with the test organism and incubated. After $24 \mathrm{~h}$ of incubation, $0.5 \mathrm{~mL}$ Kovac's indole reagent was added and shaking to observe for a colour change. There was appearance of a red ring at the surface of the medium which indicated a positive test.

\section{iv. Oxidase test}

A piece of filter paper was placed in a sterile dish and was flooded with oxidase reagent (tetramethylparaphenylenediamine dihydrochloride) and the test organism smeared across the impregnated paper. A positive result is indicated by a deep purple after 30 secs.

\section{v. Catalase test}

A loopful of isolates was individually emulsified on a clean slide with a drop of sterile distilled water. A drop of hydrogen peroxide was added. A positive result was observed indicated by a bursting bubble which gives rise to an effervescence.

\section{vi. Motility test}

A single straight stab was made at the centre of the test tubes containing the semi-solid medium about half the depth of the medium. The medium was then incubated at room temperature for $24 \mathrm{hrs}$. A positive result was observed for motility test as detected by the migration of the organism from the stab line and diffusion into the medium causing turbidity and rendering the medium opaque.

\section{vii. Sugar Fermentation test}

The sugar fermentation tests were carried out using 1 $\%(\mathrm{w} / \mathrm{v})$ of the sugars in normal peptone water containing a drop of bromothymol blue indicator. The solutions were dispensed in test tubes with inverted Durham tubes for the collection of gas. The contents in the test tubes were sterilized at $121{ }^{\circ} \mathrm{C}$ for $15 \mathrm{mins}$ and allowed to cool before inoculation. The test organisms were inoculated into the test tubes and incubated for $24 \mathrm{~h}$ at room temperature.
A positive result was noted by a change in colour from green to yellow for acid production, while gas production was indicated by displacement of the medium in the Durham tubes. Before incubation of the media, absence of gas bubbles in the Durham tubes were confirmed. An uninoculated sterile medium served as a control. The procedure was carried out using glucose, lactose and sorbitol.

\section{viii. Hydrogen Sulphide test}

Nutrient broth was prepared and poured into test tubes before sterilization at $121^{\circ} \mathrm{C}$ for 15 mins. The test organisms were aseptically inoculated into the medium after cooling using lead acetate paper. This was incubated at $37^{\circ} \mathrm{C}$ for $24 \mathrm{~h}$ and then examined for a black colour which indicates a positive result.

\section{Production of Phenazine-1-carboxylic acid (PCA) from the isolated Pseudomonas aeruginosa - $[2,16,20]$.}

The Pseudomonas aeruginosa was streaked on LuriaBertani (LB) agar plates and incubated at room temperature for $24 \mathrm{hrs}$. A single colony of $P$. aeruginosa on a LB agar plate was transferred into 100 $\mathrm{mL}$ of modified King's A broth (KA): bactopeptone $(15.0 \mathrm{~g})$, sodium chloride $(13.0 \mathrm{~g})$, glycerol $(9.0 \mathrm{~mL})$ and potassium sulphate $(1.0 \mathrm{~g})$ were all added to 1,000 $\mathrm{mL}$ distilled water; and incubated at $29-30{ }^{\circ} \mathrm{C}$ with an orbital shaker $(200 \mathrm{rpm})$ for $24 \mathrm{hrs}$. For increasing PCA production, the starter culture was transferred into an Erlenmeyer flask (1,500 mL) containing fresh modified KA medium with 1:50 bacterial dilutions and incubated for $48 \mathrm{~h}$ under the same conditions as described above. An Amberlite XAD-16 resin column was used for the PCA isolation by eluting this column with $70 \%(\mathrm{v} / \mathrm{v})$ acetonitrile in distilled water.

\section{i. Purification of the PCA}

The purification of the compound was achieved in two steps: firstly, the $\mathrm{pH}$ of the crude phenazine solution was adjusted to 2.5 and residues removed by centrifugation at 3,500 rpm for 15 mins. Secondly, this solution was separated by a liquid-liquid extraction with dichloromethane. The extracted phenazine was then purified on a silica gel column, equilibrated with dichloromethane. The optimum solvent system for the silica gel column was $90 \%(\mathrm{v} / \mathrm{v})$ dichloromethane in ethyl acetate. The yellow crystals formed after concentration, were dried, weighed and the yield, as well as the melting point determined. The procedure was repeated to obtain more yields. 


\section{International Journal of Engineering Applied Sciences and Technology, 2021 \\ Vol. 6, Issue 4, ISSN No. 2455-2143, Pages 27-33 \\ Published Online August 2021 in IJEAST (http://www.ijeast.com)} 5. Synthesis of phenazineazo-1-naphthol 5 from
PCA isolated from P. aeruginosa
The phenazineazo-1-naphthol (PCA-1N) 5 synthesis from the phenazine-1-carboxylic acid (PCA) isolated from $P$. aeruginosa is as follows (shown in scheme 1):

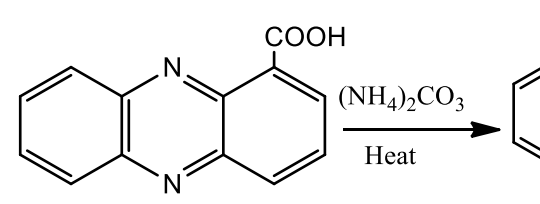

1<smiles>NC(=O)c1cccc2nc3ccccc3nc12</smiles>

2

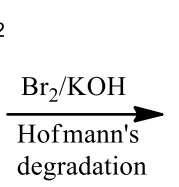<smiles>Nc1cccc2nc3ccccc3nc12</smiles><smiles>Oc1c(N=Nc2cccc3nc4ccccc4nc23)ccc2ccccc12</smiles>

5

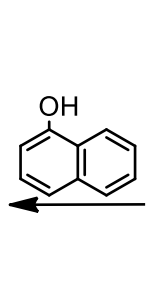

$\overbrace{0-5^{\circ} \mathrm{C}}^{(1+N=N}$

4

Scheme 1: Synthesis of phenazineazo-1-naphthol compound from the PCA

Phenazine-1-carboxylic acid 1 (0.05 g) was refluxed with 1 gram of ammonium carbonate, $\left(\mathrm{NH}_{4}\right)_{2} \mathrm{CO}_{3}$, for $4 \mathrm{~h}$ at $50{ }^{\circ} \mathrm{C}$. A mixture of solution of bromine $(8.5$ $\mathrm{mL})$ and $\mathrm{KOH}(30 \%, 3.8 \mathrm{~mL})$ was added, it was heated for $4 \mathrm{~h}$ at $50{ }^{\circ} \mathrm{C}$ to degrade the phenazine amide $\mathbf{2}$ formed (amidation) to produce phenazine amine $\mathbf{3}$ which was filtered and dried. The procedure was repeated to obtain more of the phenazine amine. The phenazine amine $\mathbf{3}(0.019 \mathrm{~g})$ was mixed with a solution of sodium nitrite $(1 \mathrm{~g})$ precooled to $0-5{ }^{\circ} \mathrm{C}$ and concentrated hydrochloric acid $(5 \mathrm{~mL})$ to form the phenazonium ion 4 in an ice bath at $0-5^{\circ} \mathrm{C}$. A solution of $1 \%$ naphthol was separately prepared and allowed to cool at $0-5^{\circ} \mathrm{C}$ for 10 mins. The cooled $1 \%$ naphthol solution was added to the phenazonium solution with stirring at $0-5^{\circ} \mathrm{C}$. The whole mixture was allowed to stand for 5 mins for complete reaction and the brownish yellow phenazineazo-1-naphthol $\mathbf{5}$ crystal formed was recovered through suction filtration. It was recrystallized using ethanol, dried in a desiccator with the weight and melting point determined.

5. Determination of the zone of Inhibition and Minimum Inhibitory Concentration Estimation (disks method) - [15-16, 20].
By using Whatman filter paper No. 1, Discs of $5 \mathrm{~mm}$ in diameter were produced by using a paper borer. After that, the prepared disks were put in suitable containers. Then, the discs were subjected to autoclaving in order to sterilize the disks (adjusting the conditions of autoclave to $121^{\circ} \mathrm{C}$ for $15 \mathrm{mins}$ ) and left to cool. Later on, the discs were allowed to suck up the sample filtrate at $50 \mu \mathrm{g} / \mathrm{mL}, 100 \mu \mathrm{g} / \mathrm{mL}, 150 \mu \mathrm{g} / \mathrm{mL}$, $200 \mu \mathrm{g} / \mathrm{mL}$, raw and $30 \mu \mathrm{g} / \mathrm{mL}$ each of control antibiotics [Augmentin ( $\mathrm{Au}$ ) and Oflocitoxin (OFX) drug discs] concentrations, maintained for later assay. The produced discs (each one) have the ability to absorb about $0.01 \mathrm{~mL}$ of the sample concentrations. The discs with concentrations were place on the prepared plates inoculated with Staphylococcus aureus, Aspergillus fumigatus and Escherichia coli and incubated for $24 \mathrm{hrs}$. The zone of inhibition was observed, measured in millimeter and the minimum inhibitory concentration estimated.

\section{EXPERIMENTAL RESULTS}

Table 1. Characterization of the isolate (Pseudomonas aeruginosa)

\begin{tabular}{|c|c|c|c|c|c|c|c|c|c|c|c|c|}
\hline \multirow[b]{2}{*}{ 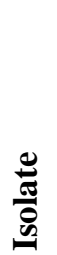 } & \multirow{2}{*}{ 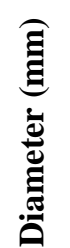 } & & & \multirow{2}{*}{ 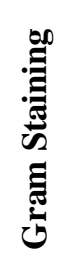 } & \multirow[b]{2}{*}{$\frac{\tilde{D}}{\frac{\tilde{W}}{\pi}}$} & \multirow[b]{2}{*}{ 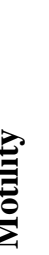 } & \multirow[b]{2}{*}{ 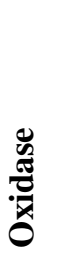 } & \multirow[b]{2}{*}{ 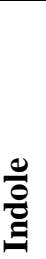 } & \multirow[b]{2}{*}{ 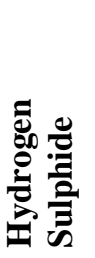 } & \multicolumn{3}{|c|}{ Sugar fermentation } \\
\hline & & $\begin{array}{l}\text { Colony and } \\
\text { Morphology }\end{array}$ & Shape & & & & & & & 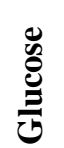 & 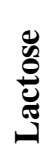 & 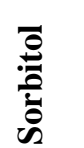 \\
\hline
\end{tabular}




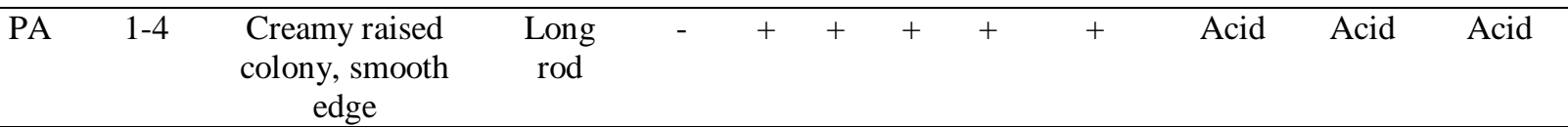

From Table 1, the results of the colony and morphology of Pseudomonas aeruginosa was confirmed to be creamy and smooth edged, long rod shaped. It was also observed that the bacterium tested negative to gram staining and positive to catalase, motility, indole and hydrogen sulphide biochemical analyses. The bacterium was able to utilize and ferment glucose, lactose and sorbitol releasing acidic gases in the presence of the sugars. The results obtained above were in agreement with Bergey et al. [18].

Phenazineazo-1-naphthol (PCA-1N) with brownishyellow colour was found to have a melting point of $86.0^{\circ} \mathrm{C}$ at $44.9 \%$ yield higher than the brightly yellow coloured natural phenazine-1-carboxylic acid (PCA) where it is modified from in reference with Nansathit et al. [2], Onunkwo and Okerulu [16] and Onunkwo et al. [20].
The UV-visible data of phenazineazo-1-naphthol was obtained at $500 \mathrm{~nm}$ which shows it absorbs at the green-blue region of the spectrum and assumes a reflection of a yellow-brown colour $\mathrm{n}-\pi^{*}$ electronic transition. The wavelength scans obtained depicts the colours of the compounds in reference to Donald et al. [19]. The Infra-red data against $\mathrm{KBr}$ showed the functional group $\mathrm{O}-\mathrm{H}$ (broad $3400.0 \mathrm{~cm}^{-1}$ ), C=C $\left(\mathrm{s} 1587.8 \mathrm{~cm}^{-1}\right), \mathrm{C}-\mathrm{C}\left(\mathrm{s} 1263.6-1207.7 \mathrm{~cm}^{-1}\right), \mathrm{C}-\mathrm{N}$ $\left(1364.2 \mathrm{~cm}^{-1}, 1328.2 \mathrm{~cm}^{-1}\right), \mathrm{C}-\mathrm{H}\left(1114.5-808.8 \mathrm{~cm}^{-}\right.$ $\left.{ }^{1}\right), \mathrm{C}=\mathrm{N}\left(\mathrm{s} 1662.4,1621.4 \mathrm{~cm}^{-1}\right), \mathrm{N}=\mathrm{N}\left(\mathrm{s} 1449.9 \mathrm{~cm}^{-1}\right)$. The HNMR data using $\mathrm{CDCl}_{3}$ of $\delta 7.000-8.917$ corresponding to aromatic protons and the C13NMR data showed slight $78.90 \mathrm{ppm}(\mathrm{R}-\mathrm{OH}), 125-160 \mathrm{ppm}$ (benzene, $\mathrm{C}=\mathrm{N}, \mathrm{C}-\mathrm{N}$ aromatic) of the compound with reference to the work of Onunkwo et al. [20], Onunkwo and Okerulu [16], Donald et al. [19] and Arijit et al. [8].

Table 2: The effect of different dilutions of the sample and control drugs against pathogenic isolate

\begin{tabular}{|c|c|c|c|c|c|c|c|c|c|}
\hline \multirow[b]{2}{*}{ Organisms } & & \multicolumn{5}{|c|}{ Phenazineazo-1-naphthol $(\mu \mathrm{g} / \mathrm{mL})$} & \multicolumn{2}{|c|}{ Control } & \multirow{2}{*}{ MIC } \\
\hline & & 50 & 100 & 150 & 200 & Raw & Au & OFX & \\
\hline Staph. Sp & & 4 & 5 & 7.2 & 20 & 25 & 15 & 13 & 50 \\
\hline E. coli & है & 8 & 13 & 18.0 & 30 & 38 & 21 & 19 & 50 \\
\hline Aspergillus. sp & & 2 & 3.4 & 4.5 & 7.9 & 10 & $\mathrm{R}$ & $\mathrm{R}$ & 50 \\
\hline
\end{tabular}

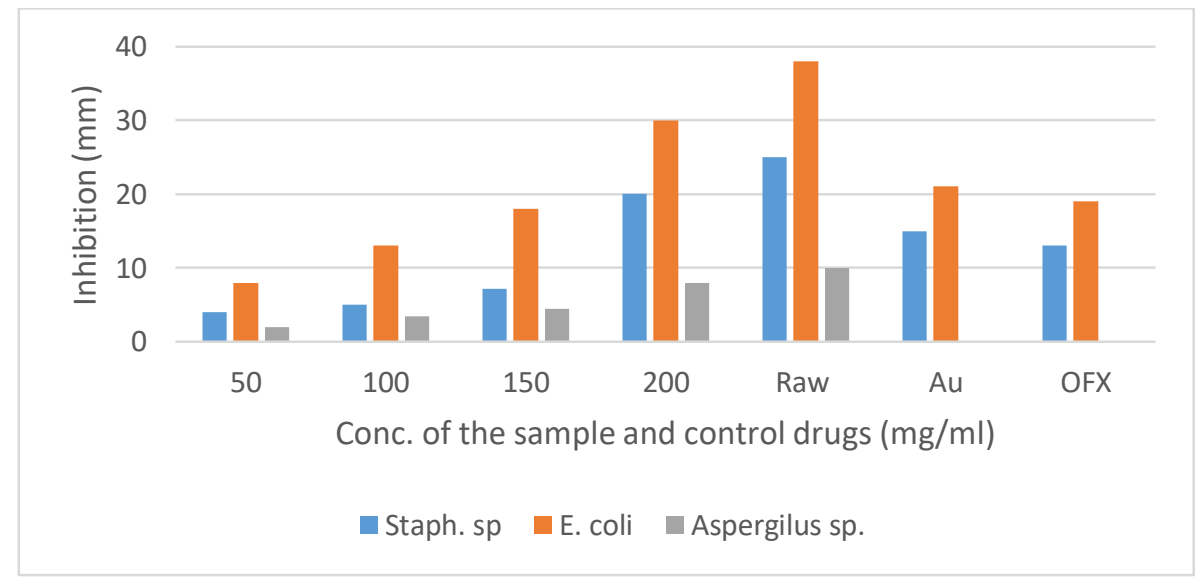

Fig.1: Antimicrobial analysis of phenazineazo-1-naphthol

From the Table 2 and Fig. 1, The concentrations of 50 $\mu \mathrm{g} / \mathrm{mL}, 100 \mu \mathrm{g} / \mathrm{mL}, 150 \mu \mathrm{g} / \mathrm{mL}, 200 \mu \mathrm{g} / \mathrm{mL}, 30$ $\mu \mathrm{g} / \mathrm{mL}$ Augmentin (Au, control drug), $30 \mu \mathrm{g} / \mathrm{mL}$
Oflocitoxin (OFX, control drug) and raw sample of the compound were able to inhibit Staphylococcus aureus at $4 \mathrm{~mm}, 5.0 \mathrm{~mm}, 7.2 \mathrm{~mm}, 20 \mathrm{~mm}, 25 \mathrm{~mm}, 15 \mathrm{~mm}$ and 


\section{International Journal of Engineering Applied Sciences and Technology, 2021 Vol. 6, Issue 4, ISSN No. 2455-2143, Pages 27-33 \\ Published Online August 2021 in IJEAST (http://www.ijeast.com)}

$13 \mathrm{~mm}$ marks respectively. The Escherichia coli was inhibited at $3.0 \mathrm{~mm}, 13 \mathrm{~mm}, 18 \mathrm{~mm}, 30 \mathrm{~mm}, 38 \mathrm{~mm}$, $21 \mathrm{~mm}$ and $19 \mathrm{~mm}$ respectively across while Aspergillus fumigatus was inhibited by the concentrations of $50 \mu \mathrm{g} / \mathrm{mL}, 100 \mu \mathrm{g} / \mathrm{mL}, 150 \mu \mathrm{g} / \mathrm{mL}$, $200 \mu \mathrm{g} / \mathrm{mL}$, and raw sample of the compound at 2.0 $\mathrm{mm}, 3.4 \mathrm{~mm}, 4.5 \mathrm{~mm}, 7.9 \mathrm{~mm}$ and $10 \mathrm{~mm}$ respectively unlike in the work of Onunkwo et al. [20] but in reference to the work of Onunkwo and Okerulu [16] and Onunkwo and Ejikeme [15], it also resisted 30 $\mu \mathrm{g} / \mathrm{mL}$ Augmentin ( $\mathrm{Au}$ ) and Oflocitoxin (OFX) control drugs from the antimicrobial analysis carried out. In general, the compound was active against the organisms when compared to the concentration of control antibiotic drugs used. The minimum inhibitory concentrations of the compound was estimated at 50 $\mu \mathrm{g} / \mathrm{mL}$ concentration. The antibiotic properties of the compound were more effective and higher than those observed in the work of Onunkwo et al. [20], Onunkwo and Okerulu [16] and Onunkwo and Ejikeme [15].

\section{CONCLUSION}

The brownish-yellow phenazineazo-1-naphthol which was synthesized from a biosynthesized phenazine-1carboxylic acid through amidation, Hoffmann degradation, diazotization and azo coupling reactions possesses antimicrobial property against Staphylococcus aereus, E. coli and Aspergillus sp. at all concentrations analyzed. The control drugs [Oflocitoxin (OFX) and Augmentin (Au)] analyzed were resisted by Aspergillus $s p$. In general, the minimum inhibitory concentration of the compound based on the analysis was estimated at $50 \mu \mathrm{g} / \mathrm{mL}$; and since the compound belongs to non-carcinogenic class of azo compounds and also produced from antibiotic (phenazine-1-carboxylic acid) it can be used as antibacterial and antifungal drug to treat infections.

\section{ACKNOWLEDGEMENTS}

This work acknowledges Tshwane University of Technology, Acadia South Africa for their assistance in the IR and NMR analysis, and also to the Vetech Research Centre and Laboratory, Institute of Management and Technology (IMT), Enugu, as well as Godfrey Okoye University, Enugu, Nigeria for their assistant in parts to the experimental and analytical aspects of this research work.

\section{REFERENCES}

[1] Laursen, J.B. and Nielsen, J., (2004). Phenazine Natural Products: Biosynthesis, Synthetic Analogues, and Biological Activity. Chemical Review. 104, pp. 1663-1685.

[2] Nansathit, A., Apipattarakul, S., Phaosiri, C., Pongdontri P., Chanthai, S.and Ruangviriyachai C., (2009). Synthesis, Isolation of Phenazine Derivatives and Their Antimicrobial Activities. Walailak Journal of Science \& Tech; 6(1): pp. 79-91.

[3] Sudhir, B.C., Bhushan, L.C., Drashanti, D.S., Makarand, R.R., (2007). Detection, Isolation and Identification of Phenazine-1-Carboxylic acid produced by biocontrol strains of Pseudomonas aeruginosa. Journal of Scientific and Industrial Research, 66: pp. 627-631.

[4] Darwesh, O.M.Moawad H., Abd El-Rahim, W.M., Barakat, O.S. and Sedik, M.Z., (2014). Production and Characterization of Bioactive pyocyanin pigment by marine Pseudomonas aeruginosa, Research Journal of Pharmaceutical, Biological and Chemical Sciences, 5(4): pp. 1203-1219.

[5] Chudgar, R.J. and Oakes, J., (2003). Dyes azo. Kirk-Othmer Encyclopedia of Chemical Technology, Wiley and sons, New York; 116: pp. 199-208.

[6] Henrich, Z., (1991). Colour chemistry: synthesis, properties and applications of organic dyes and pigments. Wiley-VCH. Weinhein, New York, Vol. 1, pp. 433- 496.

[7] Lubs, H.A., (1972). The chemistry of synthetic dyes and pigment. E. Kroyer publishing Co., New York, p. 521.

[8] Arijit, C., Prasanti, K.S., Chakradhar D., (2010). Synthesis and application of azonaphthol dyes on Wool, Silk and Nylon Fabrics. 7th international conference-TEXSCI 2010, sept 6-8, Liberec, Czech Republic. pp. 1-8.

[9] Mavrodi, D.V., Bonsall, R.F., Delaney, S.M., Soule, M.J., Phillips. G., (2001). Functional Analysis of genes for biosynthesis of pyocyanin and phenazine-1-carboxamide from Pseudomonas aeruginosa PAO1. Journal of Bacteriology 183: pp. 6454-6465.

[10] Nicholas, G. P., Nicholas, V. B., James, R. R. and Robert, W. H., (2015). Rapid Synthesis of Phenazine-1-Carboxylic Acid Derived Small Molecules from Diverse Anilines: Privileged 


\section{International Journal of Engineering Applied Sciences and Technology, 2021 \\ Vol. 6, Issue 4, ISSN No. 2455-2143, Pages 27-33 \\ Published Online August 2021 in IJEAST (http://www.ijeast.com)}

Structures for Discovery. Research \& Reviews: Journal of Medicinal \& Organic Chemistry, 2(1): pp. 69-76.

[11] Gerene, M.D., Shankar, S.I., Krzysztof, J.R., Yunxia, O’M.,George, T.R. and Bradley, E.B., (2003). Phenazine-1-carboxylic acid, a secondary metabolite of Pseudomonas aeruginosa, alters expression of immunomodulatory proteins by human airway epithelial cells. American Journal of Physiology Lung Cell Molecular Physiology, 285: pp. 584-592.

[12] Corbett, J.; Freeman, H.S.; Peter, A.T., (2000). Hair dyes: Colourants for non-textile applications. Elsevier Science, ISBN: 0444828885, pp. 456-457.

[13] Harris, D.C., (2007). Quantitative chemical analysis. W.H. Freeman Company, New York, p. 169.

[14] Arun Bahl and B.S. Bahl, (2009). Advance organic chemistry, S.Chad and Company Ltd; Ram Nagar, New Delhi-110055. pp. 11411146.

[15] Onunkwo I. C. and Ejikeme C. M., (2020). Synthesis, characterization and antimicrobial analysis of 1-(1-phenylazo)-2-naphthol, International Journal of Chemistry and Materials Research, vol. 8(1), pp. 15-19.

[16] Onunkwo, I. C. and Okerulu, I. O., (2020). Synthesis, characterization and antimicrobial analysis of phenazineazophenol from phenazine-1-carboxylic acid isolated from pseudomonas aeruginosa, International Journal of Engineering Applied Sciences and Technology, Vol. 4(11), ISSN No. 2455-2143, pp. 526-532.

[17] Singleton, P., (2004). Bacteria in Biology, Biotechnology and Medicine. West Sussex: Wiley-VCH Verlag GmmbH \& Co KGaA, Wwinheim. Germany, 6: pp. 1-58.

[18] Bergey, D.H., F.C. Harrison, R.S. Breed, B.W. Hammer and F.M. Huntoon, (1930). Bergey's Manual of Determinative Bacteriology. 3rd edition, The Williams \& Wilkins Co., Baltimore. pp. 1-589.

[19] Donald, L.P., Gany, M.L., George, S.K., James, R.V., (2009). Introduction to Spectroscopy. Cengage learning, Washington, U.S.A. Ed.4th: pp. 385-390.
[20] Onunkwo, I. C., Enemose, E. A., Ogbolu, B. O. and Okerulu, I. O., (2020). Antimicrobial analysis and characterization of phenazineazo2-naphthol synthesized from phenazine-1carboxylic acid isolated from pseudomonas aeruginosa, International Journal of Engineering Applied Sciences and Technology, Vol. 5(3), ISSN No. 2455-2143, pp. 26-32. 